\title{
Health Equity and Institutional Ethnography: Mapping the Problem of Policy Change
}

\author{
Elizabeth McGibbon ${ }^{1}$, Katherine Fierlbeck ${ }^{2}$ \& Tara Ajadi ${ }^{2}$. \\ ${ }^{1}$ Rankin School of Nursing, St. Francis Xavier University, ${ }^{2}$ Department of Political Science, Dalhousie \\ University.
}

Cite As: McGibbon, E., Fierlbeck, K. \& Ajadi, T. (2021). Health equity and institutional ethnography: Mapping the problem of policy change. Witness: The Canadian Journal of Critical Nursing Discourse, 3(2), pp 64-80. https://doi.org/10.25071.2291.117

\begin{abstract}
Health equity (HE) is a central concern across multiple disciplines and sectors, including nursing. However, the proliferation of the term has not resulted in corresponding policymaking that leads to a clear reduction of health inequities. The goal of this paper is to use institutional ethnographic methods to map the social organization of HE policy discourses in Canada, a process that serves to reproduce existing relations of power that stymie substantive change in policy aimed at reducing health inequity. In nursing, institutional ethnography (IE) is described as a method of inquiry for taking sides in order to expose socially organized practices of power. Starting from the standpoints of HE policy advocates we explain the methods of IE, focusing on a stepwise description of theoretical and practical applications in the area of policymaking. Results are discussed in the context of three thematic areas: 1) bounding HE talk within biomedical imperialism, 2) situating racialization and marginalization as a subaltern space in HE discourses, and 3) activating HE texts as ruling relations. We conclude with key points about our insights into the methodological and theoretical potential of critical policy research using IE to analyze the social organization of power in HE policy narratives. This paper contributes to critical nursing discourse in the area of HE, demonstrating how IE can be applied to disrupt socially organized neoliberal and colonialist narratives that recycle and redeploy oppressive policymaking practices within and beyond nursing.
\end{abstract}

Key words: Institutional ethnography, health equity, policy, nursing activism

Health equity (HE) is a central concern across multiple disciplines and sectors, including nursing, and it has become a key term in discourses about improving the health and wellbeing of marginalized and racialized peoples. However, the proliferation of the term has not resulted in corresponding policymaking that leads to a clear reduction of health inequities. Although there are instances of policy progress in ameliorating health inequities, the goal of this paper is to map the social organization of HE policy discourses in Canada, a form of social organization that serves to reproduce existing relations of power that stymie substantive change in policy to reduce health inequity. We also provide a template for exploring the centrality of policy in determining health outcomes of marginalized and racialized peoples. In nursing, IE is a method of inquiry for taking sides to explore socially organized practices of power (Cupit, et al., 2021). For critical perspectives in nursing, "neutrality is 
situated in the perilous territory of agreeing with oppression. If we do not speak up, we are silently agreeing" (McGibbon \& Lukeman, 2019, p. 9). Hence, critical nurse scholars such as Marie Campbell (2002) describe IE as "research for activism". This paper contributes to critical nursing discourse in the area of $\mathrm{HE}$, demonstrating how IE can be applied to disrupt neoliberal and colonialist narratives that recycle and redeploy oppressive policymaking practices within and beyond nursing.

Starting with the standpoints of HE policy advocates, we map how dominant HE narratives illustrate conceptual practices of power. This project was developed with the support of the Social Sciences and Humanities Research Council of Canada. With this funding we tracked the utilization of the term "health equity" in social sciences and health sciences research literature from 2000 to 2020 . We then analyzed how the term was understood in key texts, and finally, we interviewed individuals active in the policy realm to reflect on the ways in which HE has been operationalized within policymaking contexts. This article focuses on the final phase of the project. We begin with an overview of narrative contexts for analyzing HE. We then describe IE, focusing on a stepwise description of the theoretical and practical application of the method in the area of policymaking. Results are discussed in the context of three thematic areas: 1) bounding HE talk within biomedical imperialism, 2) situating racialization and marginalization as a subaltern space in HE discourses, and 3) activating HE texts as ruling relations. We conclude with key points about our insights into the methodological and theoretical potential of policy research using IE to analyze the social organization of power in HE policy narratives.

\section{Narrative Contexts for Analyzing HE}

HE has been consistently analyzed by nursing scholars and political and policy activists (Pauly et al., 2017), emphasizing the importance of entrenching HE in the structural realm of governance policies (Plamondon et al., 2019).
Yet, critical policy knowledge within the profession is lacking, and in many cases absent:

[Nurses] need to be more savvy about politics and policy. This means looking outside the nursing box, avoiding nursey talk and the virtue script. It means framing our messages and proposals in language that appeals to politicians, policymakers, the media and the public, and telling them compelling stories that highlight the solutions we offer (Salvage et al., 2019, p. 449).

The texts and talk of nursing continue to be dominated by apolitical, biomedical, Eurocentric narratives that obstruct nurses' HE policy contributions. However, HE is shaped by policies and achieving HE is ultimately a political process. “...[H]ealth equity as an ethical concept with normative implications is a nonstarter for health policy analysts since the term implies unfairness in the current state of distributive policies. To claim something is inequitable is to take a moral stance and place judgment and blame on specific individuals, groups, organizations and/or institutions" (Embrett \& Randall, 2014, p. 153). Defining, conceptualizing, theorizing, and operationalizing $\mathrm{HE}$ is a critical contemporary health policy goal. Yet, there is much contention about narrative meanings of HE and whether the term infers root or structural causes of illness. From a critical perspective, there is a value orientation of social justice, human rights, and Indigenous Treaty rights in the face of increasing evidence of unfairness in the distribution of ill health across populations. Illness is seen as a reflection of unequal structural distributions of economic, political, cultural, and social power, and hence unequal access to the material goods and social infrastructures necessary to sustain a high quality of life. This structural rootedness also invites inquiry into who most benefits from creating and sustaining health and social inequality. Substantive evidence demonstrates that structural determinants of health, although rarely found in national health and social policy agendas, are very strong predictive factors in determining population health outcomes 
(Braveman et al., 2011; Kickbusch, 2015; Navarro \& Muntaner, 2020).

On the other hand, from dominant neoliberal policymaking perspectives, the causes of ill health are located in individual behaviour. Despite the theoretical pluralism that underpins the role of neoliberalism in public governance, neoliberalism nonetheless largely consists of a persistent and measurable set of ideas and discourses that drive health-related policy, including belief in the primacy of individual agency. Neoliberal approaches emphasize state reduction of intervention in economic and social activities, and hence a deliberative withdrawal of welfare state social supports that enhance HE, such as a state-funded health system and universally accessible unemployment and disability benefits (Raphael, 2021). Individualistic policy intervention is focused on areas such as legislation or moral suasion that has the goal of directing individuals to "fix" their own problems, since their actions are perceived to have caused the problems in the first place.

In tandem with dominant political economies of neoliberalism, there is an overarching lack of critical social science language and analyses in the health fields, and by extension, in public policymaking within the health care domain. Oppression, human rights, and social injustice have yet to substantively inform equity discourses in public and health field policymaking (Kickbusch, 2015). Baum (2007) and Raphael (2021) have discussed government resistance to equity-oriented policies, criticizing much of the current government and public discourses about HE. Despite over three decades of integration of "equity" in public policy documents and activities, the evidence is clear that for significant numbers of Canadians, progress toward HE, and its proxy measure, improved health outcomes, remains slow and in some cases has halted or reversed direction. Although there has been overall populationbased progress, disaggregated statistics paint a different picture for marginalized and racialized Canadians. Ironically, it is precisely these groups who are the "targets" of HE policy.
Indigenous peoples and Canadians of African descent have persistently and significantly worse health outcomes when compared to the general population (Boen, 2016; Halseth \& Murdock, 2020) and poverty is a

significant predictor of morbidity and mortality in Canada and globally (Scheil-Adlung, 2014). The COVID-19 pandemic publicly exposed the historical nature of these existing inequities in health outcomes: in the province of Manitoba; $51 \%$ of people who tested positive for COVID19 self-identified as BIPOC (Black, Indigenous, People of Colour) (Government of Manitoba, 2021). People living in "ethno-cultural neighborhoods" in British Columbia had an ageadjusted COVID-19 mortality rate ten times higher than neighborhoods that were less than $1 \%$ visible minority (Subedi et al., 2020); and BIPOC populations living in Toronto made up $83 \%$ of reported COVID-19 cases (Cheung, 2020). There is also a significant correlation between high coronavirus death rates and low income, conditions of work, and visible minority status (Etowa et al., 2020), housing density (Yang \& Aitken, 2021), and low levels of education and recent immigrant status (Wherry, 2020). The central problematic for this study is the social organization of HE discourses in the policymaking context, including the proliferation of the term HE in governmental and academic discourses amidst worsening health outcomes for marginalized and racialized Canadians.

\section{IE as Method}

IE is a research method that provides a procedure for mapping the actualities of what individuals do at an everyday local level, while examining this activity in relation to its sociopolitical, economic, and cultural contextshow individual social relations are organized and co-ordinated by another set of social relations beyond the individual experience (McGibbon et al., 2010). In IE, understanding and interpreting these practices in the local "onthe-ground" world is not seen as an end in itself, as in traditional ethnography. Rather, Smith $(1999,2005)$ uses the term ethnography to explore social organization in the practical sense 
by using the experience or standpoint of a particular person or persons (in our discussion, HE policy advocates) as the point d'appui (starting point) into explaining the forms of social organization that influence people and activities in local settings, but originate beyond them (Grahame, 1998). Although IE also draws upon analyses of societal power structures, it requires examination of the genesis of these structures and precisely how everyday life is coordinated by these structures in a way that operates to produce and maintain power. The purpose is not to focus on individual behaviour, but to be able to explain to them/ourselves how power is socially organized within their/our lives and how they/we contribute to this social organization - a method of inquiry that Smith (2006) calls writing the social.

The aim of IE is to map these institutional social relations, focusing on identifying and challenging conceptual practices of power. In IE, institutional refers to institutions such as health care and governmentality as the intersection of many modes of ruling. Smith is specifically interested in the articulation of everyday work practices with extra local "relations of ruling - a complex of organized and dominant practices, including government, law, business and financial management, professional organizations, and educational institutions as well as the discourses and texts that interpenetrate these multiple sites of power" (Smith, 1987, p. 3). Smith emphasizes that relations of ruling are objectified social relations that are removed from the local and subjective experiences of people's lives, where these external loci of control are not visible within the local experience.

\section{IE and Policy Contexts}

Although IE is a well-established methodological approach for analyzing a broad range of topics, application in the health policy realm is a relatively new but growing area of investigation. Policy applications are especially salient due to the complexity of economic, cultural and political structures that drive policy. These applications include: describing how data collection and analyses related to organizational policy are taken up by principals and parents on local school planning councils (Nichols \& Griffith, 2009); tracing how governance within an educational system produces, reproduces, and subsequently enacts generations of curricular policy texts (Gerrard \& Farrell, 2013); and tracing the articulation of mandated federal policy with the social organization of teachers' work in public schools (Comber, 2012). IE has also been applied within higher order texts, such as institutional policies, to map how these texts mold and direct organizational processes and service agents' work at Labor Market Offices (Prodinger et al., 2015); how policy in United Nations international forest deliberations impact environmental policy negotiations (Eastwood, 2013); how university administrators are forced policy agents in university internationalization processes (Siiner, 2016); and how political and legal contexts direct the implementation of online sexual health services, and thus impact population health outcomes and HE (MacKinnon et al., 2020).

Here, it is important to note that positivism has dominated policy research and design over the last five decades (Shaw, 2004). A cornerstone of positivism is empiricism, the claim that $a$ priori facts and truths exist, and that these facts or truths may be acquired from direct observation. Complex relationships can thus be reduced to a set of observable and measurable truths, where objectivity is not only possible, but also desirable - policymakers themselves are not (or should not) be influenced by their own values, biases, life histories, or personal perspectives and interests. In this "desirable" context, facts and truths are unfettered by subjective analyses of oppressions such as ageism, genderism, racism, and sexism, which are reduced to analytic variables, if they are mentioned at all. This analytic approach rests on an overarching assumption of neutrality in choices about what happens to arrive on HE policy agendas or in HE policy-related research. According to Shaw, positivism is widely recognized and applied in the policy world, and "it allows analysts to assume a dispassionate, objective stance and at the same time encourages the broader policy 
community to perceive the research enterprise in this way" (p. 58). IE is thus a method that appeals to researchers and practitioners who are interested in critical perspectives of power and politics in policy, and the potential to expose the embedded or structural mechanisms through which policy sustains injustices in peoples' everyday lives.

\section{Research Methods}

The goal of the study was to critically map the ways that HE-related public policies are developed (e.g., public policymaking and its antecedents) and discursively organized (e.g., textually mediated). We specifically investigated how the ways that HE-related terms are presented and contextualized, and their impact on the nature and scope of resultant public policy. Theoretical sampling was used to recruit 18 HE policy advocates. The recruitment process adhered to a sampling grid with systematic inclusion of critical policy-oriented HE leaders. Based on our own work in the field, we populated the grid according to potential participants' geographic location in Canada, HE focus area, and the four areas of public policy advocacy listed below. Careful attention was paid to recruiting a broad cross-section of these four groups of policy-involved actors. In-depth interviews focused on learning from participants about how their everyday work unfolds and learning about how everyday problems in moving the HE agenda forward are articulated or connected to institutional processes (Rankin, 2017). Participants were asked questions such as: What is your understanding of the origins of the term 'health equity'? How would you describe the use of the concept of health equity in Canadian public policy documents, including arm's length government documents? What actions do you think need to happen in order to shift public policy towards tackling health inequity in Canada? How do you think prevailing federal and provincial/territorial governments' views or ideologies have impacted policy change for health equity over time?

The central problematic was investigated from the standpoint of four groups of HE policy advocates: 1) public policymakers working in the area of health policy in selected federal/provincial/territorial government departments and initiatives; 2) policymakers who work with non-governmental and not-forprofit organizations that have a publiclyacknowledged role in advocating for HE (e.g., women's centers; community health centers; African Canadian, Indigenous, and Immigrant organizations); 3) academics whose work involves expertise in health and public policy (e.g., political science, nursing, economics, medicine); and 4) professional practitioners (e.g., health clinicians, leaders in health and social policy fields). We were particularly interested in the daily context of their policymaking work and how this work is socially organized by another, extra-local set of institutional relations beyond the local scope of their work. Due to the justice-based nature of HE work, many of the participants worked in at least two of these policy-involved areas during their careers, and most remain actively involved in justice-related policy activism. The study received approval from researchers' university Research Ethics Boards.

Following McGibbon et al.'s (2010) IE application process, the research team developed broad a priori codes based on IE's theoretical underpinnings, for example, the disjuncture between HE meanings of policy advocates and the public policy usage of HE. Along with $a$ priori codes, we also analyzed data according to novel codes arising from the data. Analytically, thematic coding in IE directs researchers' attention to particular aspects of an account that suggest the social organization within people's stories (McCoy, 2006). Mapping of the everyday world and its relationship to ruling relations adheres to three main procedures or tasks (Smith, 1987). We undertook two of these IE tasks. First, we analyzed HE-related ideological procedures and discursive practices in extant academic literature, grey literature, and selected government and arm's length government documents (2000-2020), uncovering the largely uncritical proliferation of the term HE (McGibbon et al., 2021). Second, we engaged with HE policy advocates, discovering the social relations within their local HE work and how 
this work is articulated to a wider set of social relations that shape that work (Grahame, 1998).

\section{Findings and Discussion}

Thematic coding led to three thematic clusters: 1) the discursive organization of the word "health" in terms of how the word itself serves to ideologically and culturally confine HE discourses within biomedical and imperialist dominance, thus constraining the work of $\mathrm{HE}$ policy advocates; 2 ) the framing of racialized and marginalized peoples in HE discourses, where not only are they "invisibilized" into a subaltern, othering space, the discourses also reinforce covert processes of framing historical injustices and their resultant health impacts as individual problems that can be solved in the micro realm; and 3) the ways that HE texts are activated to reinforce and redeploy existing ruling relations as well as to invent new discourses and procedures of ruling, creating persistent and hidden structural barriers for HE policy advocates. In our analysis, we deliberatively did not adhere to rigid thematic categories due to the overarching synergies in our central problematic. For example, although it was necessary to analyze biomedical imperialism as a distinct theme, its intransigence as an overall element of social organization meant that it was salient for all three themes.

\section{Bounding HE Talk Within Biomedical Imperialism}

Study participants talked about how discursive meanings of the word "health", still grounded in historical foundations of medicalization and psychiatrization, serve to consistently divert the concept of equity from its original justice-based meanings. Once the concept of health enters into texts and talk, the ideological framing of the issue at hand becomes incrusted within a narrow orbit of analysis. For example, HE discourses rely overwhelmingly on Eurocentric and biomedical paradigms and these dominant foundations are "still based in positivist and depoliticized notions of individualism (e.g., the "patient" and the patient's nuclear family), reductionism (e.g., knowledge should be designed solely on measurable, "objective", quantitative data; lived experience is on the bottom of the evidence validity scale), and managerialism (e.g., dominance of positivist notions of what counts as efficiency; standardization of practices across even the most diverse populations; dominance of technology over relationality)" (Sinclaire et al., 2021, p. 60). Biomedical imperialism encompasses all these constructs, but further problematizes analyses within the historical violences of colonialism. It involves attention to both biological and genealogical respectability, with racial and national hierarchy as an organizing and ranking mechanism, with a dynamic tension "between the sociologies of race, ethnicity and postcolonialism, on the one hand, and the sociologies of science, biomedicine and genetics, on the other" (Fitzgerald et al., 2020, p. 1171).

Although the term HE emerged within the context of activism for social change, participants noted that it nonetheless brought with it the trappings of the word "health", which draws its ideological and practical applications from the fields of biomedicine. This process led some participants to halt or limit their use of the term HE in their advocacy and academic work. Data analysis indicated that the confluence of biomedical ideological underpinnings of the word "health" and the relatively recent term "health equity" causes the HE project to get "off track" and further marginalize HE meanings in academic and policy documents, where HE is $a$ priori framed within existing philosophical, cultural, and ideological discourses. In the context of national (Canadian) HE discourses, one participant stated: "A health equity framework also has a particular way of understanding health and that's a Western notion of health that is not applicable across all communities...there are big questions about what it means to talk about health equity in an environment where we don't really agree on what we understand is health." Another participant problematized the underlying meaning of the use of HE: "Well, I see it in my work, and in meetings with the governments, et. cetera. It is being used quite often. And I think 
when it's used, it is the veneer of political correctness without having any real goal or action to actually bring equity so that outcomes, health outcomes change".

Some participants made an important distinction between dominant, Eurocentric, Western notions of health and their assumed preferability over Indigenous and Africentric meanings of health. "[In] this kind of work, what we have to do is to resist our own history, where we have been acculturated in this biomedical model, in this Western approach". Participants also referred to health care imperialism, where generalized talk about health and HE is immediately framed as having to do with health care: "It's a thread in a number of my conversations I've had with people, and somebody called it medical or health imperialism. Like, you cannot talk about these other things because, and even if you do, they get framed around health." The cultural dominance of biomedical framings of health also serve as a continued apparatus of social control (Conrad, 2005). In the case of HE, since this control is hidden, it is followed along and supported by new and popular variations in usage. One participant described how the focus on health allowed governments to avoid expanding their horizons about HE. "...there really isn't a strong political push by society at large on the political arm and to have governments expand the horizon. And instead, we [government] will just, as issues arise we'll address those, whether it's mental health today, addiction, you know, like opioids, or cancer tomorrow, or you know, wait times yesterday, what have you." This "flavour of the day" health discourse keeps public policy in a continuous loop with little chance of sustained interruption.

\section{The Subaltern: Locating Racialized and Marginalized Peoples in HE Discourse}

Racialized and marginalized peoples are paradoxically positioned in HE discourses, a positioning that serves to maintain the historical subaltern location of the other. The term subaltern originated in the work of Antonio Gramsci, and it refers to class, caste, gender, race, language, and cultural relegation to servile, lower ranking - it continues to designate the importance of power/power over relationships in history (Prakash, 1994). "This postcolonial critique seeks to undo the Eurocentrism produced by the institution of the West's trajectory, its appropriation of the other in history" (p. 1475). These unbalanced relations of power are grounded in a colonial past and neocolonial present, including the pathways for dominant groups to reconfigure and reshape local meanings and sociopolitical structures (Anderson \&McCann, 2002; Browne et al., 2005).

Subaltern studies acknowledge the erasures of the other from "dominant discursive sites in civil society, academic and policy spaces" (Dutta, 2014, p. 70), erasures that are constructed within systemic structures and built into current and historical mechanisms that are used to reify existing knowledge and to create and re-create dominant narratives (Dutta). Study results consistently indicated a persistent pattern of racialized and marginalized peoples being invisibilized from the HE conversation.

These findings reflect our work in the first phase of this study, where we examined academic literature, government policy documents, and arm's-length government documents. We found relatively little evidence of words such as marginalization, racialization, or any of the isms and their intersections (e.g., ableism, ageism, classism, colonialism, genderism, racism, sexism), all of which are central to policy-based interventions to decrease health inequities (McGibbon et al., 2019b). Even when words such as racism or heterosexism can be found in official government documents, there is rarely any discussion (qualitative or quantitative) about what is actually meant by the terms. These words thus become discursive placeholders that further invisibilize marginalized and racialized peoples. The term HE itself serves to render invisible the complex cultural and historical meanings of justice. As one participant said: ...through the COVID time what I've come to understand even more deeply is how embedded and fractured the system is for us. I know it is for non-Indigenous 
people as well. But it's function, uh, is serving what it should do. And that is really to continue on the pathway to a genocidal world for Indigenous people. So you do it nicely so that the world doesn't see you as a bad, occupied state. So you just do it subtly, we die at high rates from diabetes, CVD [cardiovascular disease], HIV, and they're all colonially constructed. So, justice appears impenetrable.

Participants talked about how the oppressive experiences of marginalized and racialized peoples are covertly invisibilized through discourses of risk and resilience, vulnerability, individualism, and blame, rather than an acknowledgement that they are instead "under threat" of systemic oppression:

How do you sort of talk about promoting the health of communities who are adversely impacted through no fault of their own, by COVID or by other, other things, but without devolving into a discourse that seems to say what you need to do is build up some capacity to handle all this terrible stuff, all the adversity.......well-meaning public health folks, researchers, scientists, I don't know what you call them, academics, who accept a kind of uncomplicated view that people are inherently vulnerable... So if you take politics seriously and policy seriously, you would say, well, what kind of work does that kind of notion of vulnerability do?

There is thus a covert academic and policy acknowledgement of inequities in health outcomes through the perceived need to craft a parallel language that obfuscates the realities of economic and cultural oppression. As one participant explained, “...the institution, it's happy to put up some window dressing and change some language and say some words, but it has no intention of making real fundamental change". Another participant provided an example from a prominent Canadian public health organization document titled "From Risk to Resilience: An Equity Approach to COVID19 " describing how the federal government framed COVID-19 as an opportunity for people to become resilient, putting "a sort of silver lining" on the pandemic amidst exposure of deepening class and race inequalities in Canada. Other participants also problematized the discourse of individual risk. Keeping the HE focus on individuals renders invisible the collective, historical injustices experienced by the subaltern: "That that kind of approach for me is not about equity necessarily because it's about communicating that you can put in place policies to prevent individual discrimination, and you can deal with those issues in a real kind of individualized way, saying a nurse who treats someone poorly should be fired [or] people working in a particular setting need to go to sensitivity training."

The process of invisibilization was linked to parallel and synergistic strategies or mechanisms of silencing. So, even though HE policy advocates may get specific HE issues on the radar of policymakers (if not the actual policy agendas), government officials engage in unintentional and intentional systematic silencing, a hidden process cannot be easily tracked. One participant explained this process with an example about a very senior federal elected official: "And, and you can be very sure that any power he has, he will use to prevent change to the status quo and especially change to the settler colonial system. But he thinks he can just say he wore an orange shirt [to acknowledge Indigenous histories] and that does it."

Importantly, government officials operate as active agents (epistemologies of ignorance) and also through not acting (lack of policy action, filibustering/neutralization). As one participant stated: "It's not about the intentional oppression of others, it's about the protection of privilege and wealth". These processes happen in a takenfor-granted way and are thus difficult to map, due to inherent, unexamined privilege, particularly for public policy and governance officials, who are de facto largely operating from positions of privilege and superiority: 
So, I found racial superiority, class superiority, and so on and so I believe that, you know, people who have wealth privilege are in general, vested in not examining how unearned those privileges in that wealth is. And if you actually have to take equity and inequity seriously, then you have to acknowledge that you have privileges by accident or birth, not because you've worked hard and you've pulled yourself up by the bootstraps.

The discourse of racialization itself is evidence of the embeddedness and taken-for-granted nature of silencing subaltern voices because it reinforces the structural invisibility of whiteness as a racialized identity - only the subaltern are racialized, while white (and settler) people are invisibly positioned as the universal, objective, and normative standard. This standard is not without paradox as HE-related public policy documents in Canada have no demonstrable pattern of including the words "racism" or "racialization", let alone showing evidence of the white privilege and white supremacy that being racialized as white confers (McGibbon et al., 2019a). Even when policymakers allude to "race", the conversation is most often reduced to a focus on "diversity", and more recently JEDI (justice, equity, diversity and inclusion). As one participant noted during a conversation about diversity as damage control, "And the knight. Jedi knights, right. Which is of course, a bunch of white men with martial arts skills. Right. And swords." Justice, equity, diversity and inclusion language thus becomes yet another invisibilizing discourse that diverts policy away from confronting the embodied violences perpetrated against marginalized and racialized peoples, to a seemingly perpetual constellation of workshops, training sessions, government documents, and calls for research grant proposals with equity and diversity in the titles.

Invisibilizing also took the form of systematically relegating policy justice advocates to the non-space of chronic policy inaction. One participant described a situation where another policy advocate was exposing systemic discrimination in terms of government funding for services on Indigenous "reserves": It's like about $30 \%$, less than for everywhere else. Education gets $30 \%$ less, child welfare $30 \%$ less, right?... She'd go negotiate. And they'd say, Oh, yes, yes. And they'd seem to listen. And they'd say all the right things and whatever. She kept thinking she was getting somewhere. And she finally realized because they kept agreeing with her and everything and saying they were going to fix it. And then they didn't. And she said after about 15 years, she finally realized they were just stringing her along. And the negotiations were just bullshit.

Although all of the above forms of invisibilizing are described separately, the on-the-ground unfolding is entirely synergistic: literal or covert absence of certain words (e.g., racism) and even when they are used, they most often serve as discursive placeholders; covert invisibilizing through discourses of risk, resilience, and so on; and placing HE policy advocates in the nonspace of chronic and unproductive policycycling. In the next section, we illustrate how these themes are interconnected and synergistic with the textual organization of power.

\section{Activating HE Texts as Ruling Relations}

Texts are an essential form of how HE is articulated to ruling relations. Writers about $\mathrm{HE}$ are "in and within this process, which is largely invisible to them" (Campbell \& Gregor, p. 40). They take up HE writing first and foremost in these taken-for-granted contexts. One actor (writer, policymaker, researcher) in a social relation never needs to know the other actors. The text functions to make such invisible connections work. The activation of the text in question (HE discourses) is a procedure for exercising organizational power, in this case activating an individualized, largely apolitical interpretation of HE. This activation work structures the choices that anyone seeking HE information may come upon, such as researchers and academics, students of health and public 
policy, and writers of arms' length government documents that may inform policy. Smith (2005) refers to this process as an ideological circle. As Smith $(1987,1990)$ points out, ruling relations are the hidden structures that not only direct what can be known about a subject or area of investigation/ intervention about $\mathrm{HE}$, but how it can be historically and currently examined. "Predominantly, the only tools we have are those that are available within the established frameworks that our professional/activist discourse provides" (Rankin, 2017, p. 7). In the objectified, ideological version of HE knowledge-making, there is no way back to the needs of people under threat, or the needs of policy advocates who work to improve their quality of life. Medical imperialism as described in our first theme, causes the word "health" to be bound within the pre-existing texts of historical imperialism. Power and politics are systematically subverted in the interests of ruling relations such as colonialism, racialization, and marginalization, where "ruling interests can be put in place objectively through administration, policymaking and program implementation" (Campbell \& Gregor, 2002, p. 39).

The discursive uses of HE form an intricate substrate that activates the texts of ruling relations, including the apparatus of capitalism, Eurocentrism, colonialism, and patriarchy. An apparatus has an actual, tactical purpose and is always positioned within a power relation (Agamben, 2009). Some participants framed these processes as structural violence. As Farmer (2004) explains, "the concept of structural violence is intended to inform the study of the social machinery of oppression" (p. 307). This textual organization of power is invisible and constitutes a form of structural violence. Structural violence, first described by Johan Galtung (Galtung, 1969), is distinguished from personal or direct violence, where the actor(s) may be directly identified, such as damage or death by fist, gun or knife; whereas, in structural violence (built into, embedded in societal structures), there is no such actor. For Galtung, "structural violence is also a blueprint - an abstract form without social life - used to threaten people into subordination" (p. 172).

Cooper and Whyte (2018) further differentiated direct violence from institutional violence, the latter being a form of joint policy making that reflects a detached administration of violence in institutional policies, "a more insidious targeting of subject groups and populations in ways that produce and increase the likelihood of other, ongoing, violent circumstances occurring" ( $p$. 1). Importantly, institutional violence is organized and administered through publicly accepted, legitimate means (Grover, 2019), such as legislative bills and resultant policies that entrench poverty in marginalized and racialized communities (McGibbon, 2021). In the context of violence, one participant talked about how Indigenous peoples' bodies are treated and perceived in the systemic realm:

....justice doesn't go there, there's no health, there's only violence and murder and removal from that, right? So that functional state, when you look at the analysis around equity, our spatiality is impenetrable to equity. It's impenetrable singularly, and that's why the murders continue, right? So that justice can't say, this is an Indigenous body that was murdered, charge somebody, and hold somebody accountable. Right? It doesn't work. So that's one of the reasons that equity is a very difficult concept.

Another participant described how violence is also individualized and removed from structural contexts: "They say oh you know, native women there are prone to that kind of thing or you know, East Indians or welfare. So it was just this constant association of interpersonal violence with racialized and marginalized groups you know, so I had no choice but to really study justice and equity pertaining particularly to antiwoman sentiments, racism and classism." When discussing structural contexts for HE, another participant also emphasized the embeddedness of violence:

...violence is every day. It's an everyday reality for people and just because the particular trauma maybe isn't there right now, but the impact of the violence is 
just forever. And it's structural. So, this attention to structures is the big difference. People still are limited by a neoliberal discourse that actually, in my view, they haven't been challenging. If you're doing equity work, you have to challenge the neoliberal discourse. You have to rail against it, you have to point the finger at new managerialism.

When asked to talk about changing meanings of HE over time, participants unanimously pointed to the evolution of HE away from its original justice roots: "Health equity is used in some ways as a kind of bureaucratized way of understanding a whole series of complex relationships... it's interesting that we've shifted from a kind of social justice oriented way of thinking about equity to what is now more kind of, I think a more diluted way of thinking about equity". This discursive management of HE talk in the structural realm of ruling relations serves to effectively roll back progress in sustaining a root-cause analyses and hence root cause focused policymaking. In tandem with this process is a consistent resistance to sustaining HE connections with social justice, and as one participant identified, shifting the choice of words (e.g., inequality, inequity) ultimately has no impact on public policy:

In theory it's [the use of the word equity] supposed to kick it up to a higher level, in that it evokes the normative aspect of being unfair and unjust...the long and the short of it is that we may be using the word health and equity [and] people may recognize that this is introducing the normative aspect in terms of unfairness, unjustness, avoidability, but it has no practical impact on anything. I don't see any evidence that the use of the term equity as opposed to inequality or equality is leading to any significant change in communication and policy, and so forth.

Participants also identified the articulation of shifting HE discourses with larger or ruling processes that serve to obscure the realities of inequitable distribution of wealth and hence access to the material resources that sustain equity in the social determinants of health:

It has this implication of unfairness and, unjustice, but the way it plays out, I think it's simply making people using the term feel better about themselves rather than having practical impact on how this might be playing out in public policy...the use of the word equity allows people to interpret it in any way they want...everybody accepts the concept of equity or social determinants in a practical sense of more than biology or lifestyle, but there's no systematic effort...

In the context of activating $\mathrm{HE}$ texts as ruling relations, participants talked about how the ruling classes themselves are uniquely positioned to keep the ruling relations of HE discourses intact. (e.g., "death of Marxism as a discursive environment"). Policymakers are largely positioned in dominant social identities and have a vested interest in maintaining the status quo, a process that, at the same time, serves to maintain and increase class, race, and gender hierarchies. One participant related the theme of health care imperialism to the ruling classes:

I think it's healthcare imperialism too. As soon as we start talking about how health shuts out everything else that is important, such as poverty and class. Well, now that I'm having a better understanding of Marxist institutionalism, I think it's about class interests, dominant class interests. It doesn't serve their interests to increase the minimum wage, to do all that, to make all these other policy changes that would improve social wellbeing and health for all members of society.

Results provided consistent evidence of the disjuncture between the on-the-ground everyday experiences of policy advocates and the ruling relations of the HE policy context. For community leaders and academics who work at the interface between lobbying policymakers for socially just public policy, on the one hand, and 


\section{See it. Speak it. Write it. Change it.}

the racialized and marginalized peoples who suffer and die due to public policies on the other, this liminal space is imbued with the intransigent and hidden privileges of class, whiteness, and largely maleness. Participants often described situations that illustrated a disjuncture or bifurcation between common-sense versions of $\mathrm{HE}$ action in the public sphere and what is actually happening on-the-ground in the policymaking realm, such as misuse or misapplication of the words "community-based" and "consultation" and temporary co-optation with promises of integration in the "next budget cycle", or provision of offices and websites in lieu of actual public policy planning and intervention.

The ultimate result is a form of discourse cycling as a policy strategy at the border between policy advocates who work to put $\mathrm{HE}$ on policy agendas and actual government officials (See Figure 1). Discourse cycling is a process wherein every time a radical discourse plants itself on the political agenda (e.g., "defund the police"), a counternarrative emerges to neutralize or draw attention away from it (e.g., "what should we do about the rise of violent crime?"). This same process is used to neutralize HE claims that are publicly articulated. For example, mounting evidence of worsening health outcomes for marginalized and racialized peoples provides an exogenous shock that is difficult for governing officials to ignore. New discourses, such as HE, COVID-19 strategic interventions, and the health of "at risk" and "diverse" populations become firmly planted on policy agendas, at least as discursive place markers. From the standpoint of HE policy advocates, HE interventions are then obscured and neutralized by dominant and strategic counternarratives of public policymakers in governance positions (e.g., "fiscal restraint", "efficiency", "equality", "evidence-based medicine", and so on). For example, HE policy advocates work to get an issue on the policy agenda, then public policymakers make it look as if action is happening - which is actually a strategy initiative to make sure HE is symbolically on the table, while at the same time working to actually keep it off the table (discursive slippage). This cycling process explains why and how HE discourses return to the status quo of an apparently infinite loop of policy inaction - an effective mechanism and public space where ruling relations can operate without scrutiny.

Figure 1: HE Discourse Policy Cycling

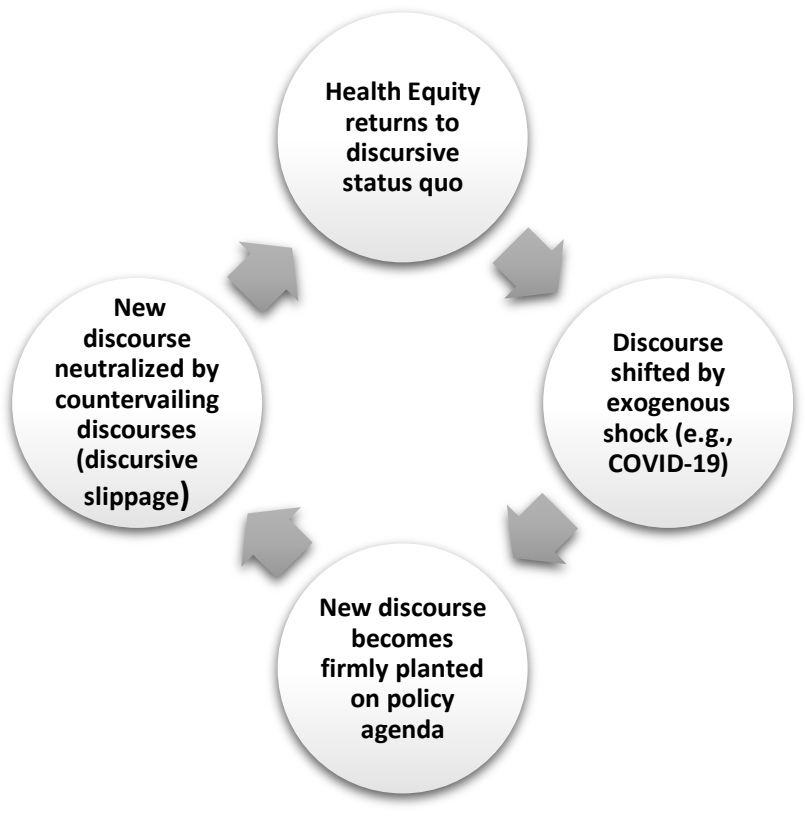


It is important to note that the systematic and rather logical process of HE discourse policy cycling belies the structural violence and social murder that it produces and reproduces. All along these pathways are actual people, neighborhoods, communities, and nations. Table 2 summarizes the process of HE policy cycling, with an emphasis on strategic countervailing discourses that serve to neutralize policy progress.

\begin{tabular}{|c|c|}
\hline New discourse & Strategic countervailing (neutralizing) discourse \\
\hline \multirow{4}{*}{ Health Equity } & HE policy action not possible due to lack of economic sustainability \\
\hline & HE policy action not possible- - time frame not feasible \\
\hline & Public is not ready for conversation (strategic paternalism) \\
\hline & $\begin{array}{l}\text { Discourse of commitment and work ethic substitutes for action: "We're taking this } \\
\text { very seriously", "We're already committed to/ working hard on this issue") }\end{array}$ \\
\hline \multirow{4}{*}{$\begin{array}{l}\text { COVID-19 } \\
\text { Strategic } \\
\text { Interventions }\end{array}$} & Cooptation of "target" groups \\
\hline & Claims of the need for more evidence before acting to address health inequities \\
\hline & $\begin{array}{l}\text { Emphasis on lack of system capacity heading into crisis (thus legitimizing lack of } \\
\text { action) }\end{array}$ \\
\hline & $\begin{array}{l}\text { Emphasis on personal culpability due to pre-existing behavioural/moral deficits: } \\
\text { "Since people weren't being responsible with their health before the pandemic, of } \\
\text { course they will be sicker." (Overlaps with at-risk countervailing discourse below) }\end{array}$ \\
\hline \multirow{3}{*}{$\begin{array}{l}\text { Health of 'at- } \\
\text { risk', 'diverse' } \\
\text { populations }\end{array}$} & Focusing on individualism: Their health problems originate in lifestyle deficits \\
\hline & $\begin{array}{l}\text { Hiding structural causes: health is compromised due to incapacity to follow dietary } \\
\text { and exercise recommendations }\end{array}$ \\
\hline & $\begin{array}{l}\text { Employing "diversity" language as buffer for not acting to address systemic wrongs } \\
\text { (e.g., sexism, racism) - employing diversity discourse as damage control. }\end{array}$ \\
\hline
\end{tabular}

\section{Conclusions}

The term HE increasingly dominates academic and policy texts and talk of improving health outcomes for peoples "at risk". As evidenced by this study, regardless of how HE is defined in these discourses, its use and misuse is articulated to conceptual practices of power that largely keep HE action in a sort of infinite loop of ineffective policy cycling. This paper illustrates, makes visible, many of the hidden practices that create and sustain these processes, and thus demonstrates entry points for exposing and tackling root policymaking practices that provide the structural supports of oppression. These results have far-reaching implications for nursing, a profession where even foundational policy knowledge is not yet a substantive part of overall narratives in practice, research, or education, despite calls for development of political and policy competence and civic participation (Cervera-Gasch et al. (2021). "...nurses must know in greater depth the mechanisms and procedures by which the social contract between governments and citizens is established through public policies" (p. 1). Nurses are not often invited to the policy table or subsequently by the media, where policy progress, or lack of it, are communicated to the public. Put simply, with some notable exceptions, nurses are not yet seen as credible public witnesses to the costs and consequences of health inequities. This study provides a map for nurses to enact critical policy analyses that can name and confront the hidden processes of oppressive policy cycling in HE discourses, and myriad other policy-created injustices. 


\section{References}

Agamben, G. (2009). "What is an apparatus?" and other essays. Stanford University Press.

Anderson, J.M., \& McCann, E. K. (2002). Toward a post-colonial feminist methodology in nursing research exploring the convergence of post-colonial and feminist scholarship. Nurse Researcher, 9, 720.

https://doi.org/10.7748/nr2002.04.9.3.7.c61 8

Baum F. (2007). Cracking the nut of health equity: Top down and bottom up pressure for action on the social determinants of health. Promotion \& Education, 14(2):9095.https://doi.org/10.1177/1025382307014 0022002

Boen, C. (2016). The role of socioeconomic factors in Black-White health inequities across the life course: Point-in-time measures, long-term exposures, and differential health returns. Social Science and Medicine, 170, 63-76.

https://doi.org/10.1016/j.socscimed.2016.1 0.008

Braveman, P. A., Kumanyika, S., Fielding, J., LaVeist, T., Borrell, L. N., Manderscheid, R., \& Troutman, A. (2011). Health disparities and health equity: The issue is justice. American Journal of Public Health, 101, S149-S155. https://doi.org/10.2105/AJPH.2010.300062

Browne A., Smye, V., \& Varcoe, C. (2005). The relevance of postcolonial theoretical perspective to research in Aboriginal health. Canadian Journal of Nursing Research, 37, 1637.

Campbell, M. L. (2002). Research for activism and institutional ethnography: Understanding social organization from inside it. Paper presented at the Sociology for Changing the World: Political Activist Ethnography Conference, Sudbury, Canada.

Campbell, M. \& Gregor, F. (2002). Mapping social relations: A primer in doing institutional ethnography. University of Toronto Press.

Cervera-Gasch, A., Mena-Tudela, D., CastroSánchez, E., Santillan-Garcia, A., AndreuPejó, L., \& González-Chordá, V. M. (2021). Necessary political competences for nurses from the perception of the student body: Cross-sectional study in Spain. Nurse Education Today, 109, 105229. https://doi.org/10.1016/j.nedt.2021.105229

Cheung, J. (2020). Black people and other people of colour make up $83 \%$ of reported COVID-19 cases in Toronto. CBC News, July 30, 2020.

Comber, B. (2012). Mandated literacy assessment and the reorganisation of teachers' work: Federal policy, local effects. Critical Studies in Education, 53(2), 119-136. https://doi.org/10.1080/17508487.2012.672 331

Conrad, P. (2005). The shifting engines of medicalization. Journal of Health and Social Behavior, 46(1), 3-14. https://doi.org/10.1177/0022146505046001 02

Cooper, V., \& Whyte, D. (2018). Grenfell, austerity, and institutional violence. Sociological Research Online. doi:1360780418800066. https://doi.org/10.1177/1360780418800066

Cupit, C., Rankin, J., \& Armstrong, N. (2021). Taking sides with patients using institutional ethnography. Journal of Organizational Ethnography, 10(1), 21-35. 
http://dx.doi.org/10.1108/JOE-12-20190048

Dutta, M. J. (2014). A culture-centered approach to listening: Voices of social change. International Journal of Listening, 28(2), 67-81. https://doi.org/10.1080/10904018.2014.876 $\underline{266}$

Eastwood, L. E. (2013). The social organization of policy: An institutional ethnography of UN forest deliberations. Routledge.

Embrett, M.G., \& Randall, G.E. (2014). Social determinants of health and health equity policy research: Exploring the use, misuse, and nonuse of policy analysis theory. Social Science \& Medicine, 108, 147-155. https://doi.org/10.1016/j.socscimed.2014.0 3.004

Etowa, J., Kohoun, B., Etowa, E.B., Kiros, G., Mbagwu, I., Muray, M., Dabone, C., Ubangha, L., \& Nare, H. (2020). "Leaving no one behind": COVID-19 response in Black Canadian communities. Witness: The Canadian Journal of Critical Nursing Discourse, 2(2), 124-130. https://doi.org/10.25071/2291-5796.84

Farmer, P. (2004). An anthropology of structural violence. Current Anthropology, 45(3), 305-325. https://doi.org/10.1086/382250

Fitzgerald, D., Hinterberger, A., Narayan, J., \& Williams, R. (2020). Brexit as hereditary redux: Imperialism, biomedicine and the NHS in Britain. The Sociological Review, 68(6), 11611178. https://doi.org/10.1177/0038026120914 177

Galtung, J. (1969). Violence, peace, and peace research. Journal of Peace Research, 6(3), 167-191.

http://www.jstor.org/stable/422690

Gerrard, J., \& Farrell, L. (2013). 'Peopling' curriculum policy production: Researching educational governance through institutional ethnography and Bourdieuian field analysis. Journal of Education Policy, 28(1), 1-20.

https://doi.org/10.1080/02680939.2012.664 $\underline{288}$

Government of Manitoba (2021). COVID-19 infections in Manitoba: Race, ethnicity, and Indigeneity, External Report, March 1, 2021. https://www.gov.mb.ca/health/publichealth/ surveillance/docs/rei_external.pdf

Grahame, P.R. (1998). Ethnography, institutions, and the problematic of the everyday world. Human Studies, 21(4), 347-360.

https://doi.org/10.1023/A:1005469127008

Grover, C. (2019). Violent proletarianisation: Social murder, the reserve army of labour and social security 'austerity' in Britain. Critical Social Policy. 39(3), 335-355. https://doi.org/10.1177/0261018318816932

Halseth, R., \& Murdock, L. (2020). Supporting Indigenous self-determination in health: Lessons learned from a review of best practices in health governance in Canada and internationally. National Collaborating Centre for Indigenous Health. https://www.nccih.ca/495/Supporting_Indi genous_selfdetermination_in_health__Lessons_learne d_from_a_review_of_best_practices_in_he alth_governance_in_Canada_and_Internati onally.nccih? $\mathrm{id}=317$

Kickbusch, I. (2015). The political determinants of health-10 Years On. BMJ, (Clinical research ed.), 350, h81. https://doi.org/10.1136/bmj.h81

MacKinnon, K. R., Gómez-Ramírez, O., Worthington, C., Gilbert, M., \& Grace, D. (2020). An institutional ethnography of political and legislative factors shaping online sexual health service implementation in Ontario, Canada. 
Critical Public Health, 1(11). https://doi.org/10.1080/09581596.2020.185 4182

McCoy, L. (2006). Keeping the institution in view: Working with interview accounts of everyday experience. In D. Smith (Ed.), Institutional ethnography as practice (109126). Rowman \& Littlefield.

McGibbon, E. (2021). The COVID-19 pandemic: On the everyday mechanisms of social murder. Critical Studies: An International and Interdisciplinary Journal, 16(1), 35-42.

McGibbon, E., Fierlbeck, K., \& Ajadi, T. (2019a). Institutional ethnography as feminist policy analysis: A Canadian case study. Panel presentation, International Public Policy Association, 3rd Annual Conference, Montreal, QC, June, 2019

McGibbon, E., Fierlbeck, K., \& Ajadi, T. (2019b). Mapping health equity in Canadian public policy: Ruling relations and the dynamics of oppression. Panel presentation, International Public Policy Association, $3^{\text {rd }}$ Annual Conference, Montreal, QC, June, 2019

McGibbon, E., Fierlbeck, K., \& Ajadi, T. (2021). Policy narratives in Canadian health equity discourses. Panel presentation, International Public Policy Association, 5th Annual Conference, Barcelona, June, 2021 (Virtual).

McGibbon, E., \& Lukeman, S. (2019). Critical social justice: The moral imperative for critical perspectives in nursing. Witness: The Canadian Journal of Critical Nursing Discourse, 1(1), 3-12. https://doi.org/10.25071/2291-5796.21

McGibbon, E., Peter, E., \& Gallop, R. (2010). An institutional ethnography of nurses' stress. Qualitative Health Research, 20(10), 1353-1378. https://doi.org/10.1177/1049732310375435
Navarro, V., \& Muntaner, C. (2020). Political and economic determinants of population health and well-being: Controversies and developments. Routledge.

Nichols, N., \& Griffith, A. I. (2009). Talk, texts, and educational action: An institutional ethnography of policy in practice. Cambridge Journal of Education, 39(2), 241-255. https://doi.org/10.1080/03057640902902286

Pauly, B., Shahram, S.Z, Dang, P.T.H, Marcellus, L., \& MacDonald, M. (2017). Health equity talk: Understandings of health equity among health leaders. AIMS Public Health, 4(5): 490-512. https://doi.org/10.3934/publichealth.2017.5 .490

Plamondon, K.M., Caxaj, C.S., Graham, I.D., \& Bottorff, J.L. (2019). Connecting knowledge with action for health equity: A critical interpretive synthesis of promising practices. International Journal of Equity in Health, 18, 202. https://doi.org/10.1186/s12939-019-1108-x

Prakash, G. (1994). Subaltern studies as postcolonial criticism. The American Historical Review, 99(5), 1475-1490. https://doi.org/10.2307/2168385

Prodinger, B., Rudman, D. L., \& Shaw, L. (2015). Institutional ethnography: Studying the situated nature of human occupation. Journal of Occupational Science, 22(1), 71-81.

https://doi.org/10.1080/14427591.2020.173 $\underline{1845}$

Rankin, J. (2017). Conducting analysis in institutional ethnography: Guidance and cautions. International Journal of Qualitative Methods, 16. https://doi.org/10.1177/1609406917734472

Raphael, D. (2021). Raising the volume on the social determinants of health in Canada and elsewhere. In E. A. McGibbon (Ed.), 
Oppression: A Social Determinant of Health, (2nd ed., 44-62). Fernwood Publishing.

Salvage, J., Montayre, J., \& Gunn, M. (2019). Being effective at the top table: Developing nurses' policy leadership competencies. International Nursing Review, 66(4), 449452. https://doi.org/10.1111/inr.12567

Scheil-Adlung, X. (2014). Response to health inequity: The role of social protection in reducing poverty and achieving equity. Health Promotion International, 9 Suppl 1:i59-67. https://doi.org/10.1093/heapro/dau030

Shaw, K.M. (2004). Using feminist critical policy analysis in the realm of higher education: The case of welfare reform as gendered educational policy. The Journal of Higher Education, 75(1), 56-79. https://doi.org/10.1080/00221546.2004.117 $\underline{78896}$

Siiner, M. (2016). University administrators as forced language policy agents: An institutional ethnography of parallel language strategy and practices at the University of Copenhagen. Current Issues in Language Planning, 17(3-4), 441-458. http://dx.doi.org/10.1080/14664208.2016.1 204058

Sinclaire, M., Schultz, A., Linton, J., \& McGibbon, E. (2021). Etuaptmumk (TwoEyed Seeing) and ethical space: Ways to disrupt health researchers' colonial attraction to a singular biomedical worldview. Witness: The Canadian Journal for Critical Nursing Discourse, 3(1). https://doi.org/ 10.25071/2291-5796.94

Smith, D. E. (1987). The everyday world as problematic: A Feminist Sociology Northeastern University Press.

Smith, D. E. (1999). Writing the social: Critique, theory and investigations. University of Toronto Press.
Smith, D. E. (2005). Institutional ethnography. Alta Mira Press.

Smith, D. E. (2006). Institutional ethnography as practice. Rowman \& Littlefield.

Subedi, R., Greenburg, L., \& Turcotte, M. (2020). COVID-19 mortality rates in Canada's ethno-cultural neighborhoods. Statistics Canada, October 28, 2020.

Wherry, A. (2020). One country, two pandemics: What COVID-19 reveals about inequality in Canada. $C B C$ News, Jun 13, 2020.

Yang, F-J., \& Aitken, N. (2021). People living in apartments and larger households were at higher risk of dying from COVID-19 during the first wave of the pandemic. Statistics Canada, April 13, 2021, Catalogue no. 452800.

The authors report no conflict of interest.

Funding associated with the study was provided by the Social Sciences and Humanities Research Council.

Ethical approval was provided by St. Francis Xavier University Research Ethics Board and Dalhousie University Research Ethics Board.

Data availability statement: Data is not available to the public as per research ethics protocols and participant consents in place at the time of the study.

Received Nov 1, 2021; Revised Dec 6 ${ }^{\text {th }}$, 2021; Accepted Dec $7^{\text {th }}, 2021$. 